\title{
Glycolytic Activity in Extracts of Young Rat Skin ${ }^{1}$
}

\author{
I. A. Bernstein and Dorothy Sweet \\ From the Department of Dermatology, Medical School, \\ Iniversty of Michigan, Ann Arbor, Michigan
}

Received April 3, 1958

\section{INTRODUCTION}

The existence of the glycolytic sequence of enzymes in rat skin is suggested by the data of a number of investigators. For example, Barron $e t$ al. (1) found that the endogenous, anaerobic evolution of $\mathrm{CO}_{2}$ in slices of rat skin was inhibited by iodoacetate, fluoride, and glyceraldehyde. Dixon and Needham (2) reported that their investigation into the mechanism of vesicant action indicated that the skin had a "phosphorylative type" of mechanism for the utilization of glucose similar to that in muscle. In addition, several laboratories have apparently demonstrated the presence of hexokinase in rat skin [cf. $(1,2)]$. A more direct picee of cvidence for the glycolytic mechanism is the demonstrated conversion of $\mathrm{FDP}^{2}$ to an equimolar mixture of PG and PGA catalyzed by an extract of rat skin (3). The present paper presents results which confirm the existence of the individual glycolytic enzymes and indicate the presence of a "DPN-requiring" glycerophosphate dehydrogenase in rat skin.

\section{Methods}

\section{Preparation of the Tissue Extracts}

The whole skins (less the subcutaneous fat) of young rats, $2-7$ days old, were ground in a mortar for $10 \mathrm{~min}$. at $0^{\circ}$ with $1.5 \mathrm{vol}$. of $5 \times 10^{-3} \mathrm{M}$ potassium phosphate

${ }^{1}$ Preliminary report of this work was presented before the American Chemical Society, Miami, April, 1957.

2 The following abbreviations have been used in this paper: phosghoglyceric acid (PGA), phosphoglycerol (PG), diphosphopyridine nucleotide (DPN), reduced DPN (DPNH), fructose 1,6-diphosphate (FDP), adenosine 5'-phosphate (AMP), adenosine 5'-diphosphate (ADP), adenosine 5'-triphosphate (ATP), fructose 6-phosphate (F6P), glucose 1-phosphate (G1P), glucose 6-phosphate (G6P), phosphoglyceraldehyde (PGAId), inorganic phosphate (Pi), dihydroxyacetone phosphate (I)HAP), phosphoenolpyruvate (PEP), ribose 5-phosphate (R5P), trichloroacetic acid (TCA), perchloric acid (PCA), optical density at $340 \mathrm{~m} \mu\left(D_{340}\right)$, and ethylenediaminetetraacetic acid (EDTA). 
buffer, $\mathrm{pH} 7.8$, and 1 vol. of glass powder (Pyrex). The supernatant solution obtained by centrifugation at about $10,000 \times g$ for $10 \mathrm{~min}$. at $2^{\circ}$ contained $2.9 \mathrm{mg}$. protein nitrogen/ml. and was used as the "crude extract." The "60\% $\left(\mathrm{NH}_{4}\right)_{2} \mathrm{SO}_{4}$ supernatant" (containing $0.10 \mathrm{mg}$. protein nitrogen $/ \mathrm{ml}$.) was prepared by adding $1.5 \mathrm{vol}$. of saturated $\left(\mathrm{NH}_{4}\right)_{2} \mathrm{SO}_{4}, \mathrm{pH} 7.5$, at $2^{\circ}$ to the "crude extract" and discarding the resulting precipitate.

\section{Incubation Procedures}

Experiments with "crude extract" were carried out in Warburg respirometer vessels at $37^{\circ}$ with $5 \% \mathrm{CO}_{2}-95 \% \mathrm{~N}_{2}$ as the gas phase, and final concentrations of $7 \times 10^{-3} M$ FDP, $1.2 \times 10^{-3} M$ DPN, $1.5 \times 10^{-3} M \mathrm{Pi}, 10^{-2} M$ fluoride and $5 \times 10^{-2}$ $M \mathrm{KHCO}_{3}$. (Acidic components were adjusted to $\mathrm{pH} 7.8$ with $\mathrm{KOH}$ before addition.) Three-tenths milliliter of "crude extract" was used per milliliter of reaction mixture. Experiments were terminated by the addition of $0.1 \mathrm{ml}$. of cold TCA $/ \mathrm{ml}$. of incubation mixture when the evolution of $\mathrm{CO}_{2}$ from the buffer had ceased.

All experiments involving spectrophotometric assay were run at $37^{\circ}$ in cuvettes in a Beckman DU spectrophotometer. The reactants used will be described below. When "crude extracts" were to be used in spectrophotometric procedures, the preparations were filtered.

\section{Filter-Paper and Ion-Exchange Chromatography of Phosphate Esters}

Filter-paper chromatography of phosphorylated compounds was carried out in the basic and acidic solvents described by Bandurski and Axelrod (4).

The conditions for the ion-exchange chromatography utilizing the gradient-elution technique of Hurlbert et al. (5) were as follows: $11 \mathrm{~cm} . \times 0.64 \mathrm{sq} . \mathrm{cm}$. column of a styrene type, quaternary ammonium anion resin (Dowex 1) (10\% eross-linkage), 200-400 mesh (with "fines" removed) in the $\mathrm{HCOO}^{-}$form; $100 \mathrm{ml}$. mixing flask containing water initially and $250 \mathrm{ml}$. of $1 \mathrm{~N} \mathrm{NH}_{4} \mathrm{OOCH}$ in the reservoir. The samples to be chromatographed were neutralized to phenol red, diluted to $100 \mathrm{ml}$., and passed

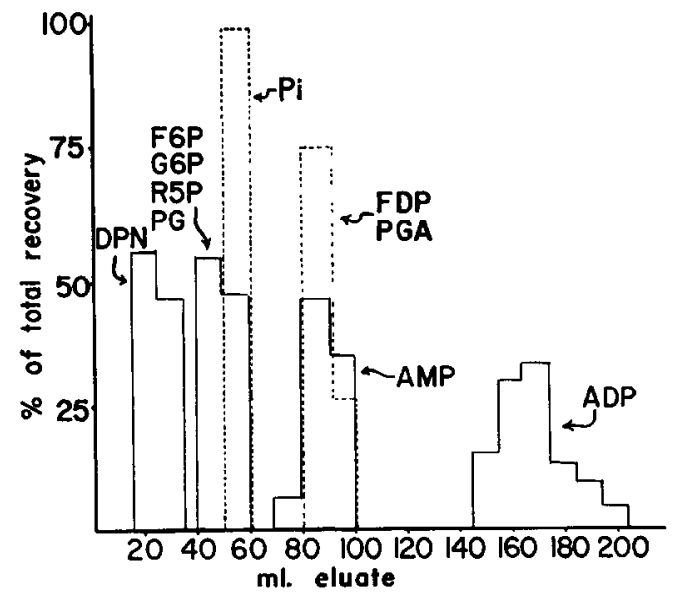

Fig. 1. Ion-exchange chromatography of phosphate esters with gradient elution. Conditions used are described in the text. Approximately $20 \mu$ moles of each compound was used. 


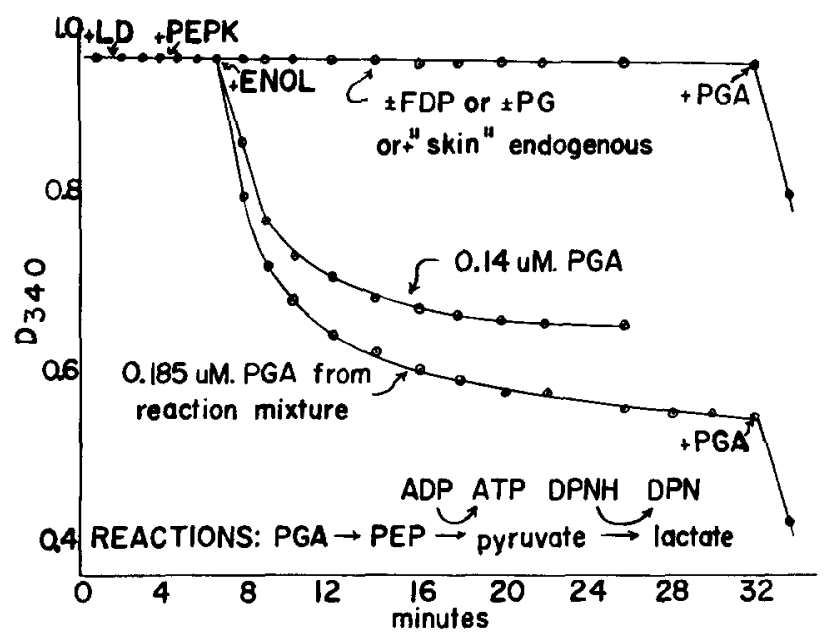

FIg. 2. Enzymic assay of PGA. Components: about $6.7 \times 10^{-5} M \mathrm{PGA}, 3 \times 10^{-}$ $M \mathrm{MgCl}_{2}, 3 \times 10^{-4} M$ ADP, $1.5 \times 10^{-1} M$ DPNH, $1.7 \times 10^{-2} M$ phosphate, pH 7.0 , and 5 units lactic dehydrogenase (LD), 2 units phosphoenolpyruvokinase (PEPK), and 0.1 unit enolase (ENOL) per $3 \mathrm{ml}$. final volume. The oxidation of $1 \mu$ mole DPNH results in a $-\Delta D_{340}$ of 2.07 .

through the column. The column was washed with $100 \mathrm{ml}$. of water prior to elution. The rates of inflow and outflow from the mixing flask were equal during the elution. Figure 1 presents an elution curve of some of the phosphorylated derivatives involved in glycolysis.

\section{Analytical Procedures}

Inorganic phosphate was determined as described by Gomori (6) and organic phosphate in the same manner after hydrolysis to inorganic phosphateby ashing with conc. $\mathrm{H}_{2} \mathrm{SO}_{4}$ and $\mathrm{H}_{2} \mathrm{O}_{2}$. Fructose phosphates were determined by the "resoreinol" assay of Roe (7) and by the enzymic procedure of Slater (8). Reducing sugar was measured by the Nelson modification (9) of the technique of Somogyi (10). G6P was determined in this way and by the enzymic procedure of Slater (8).

$P G A$ was assayed as organic phosphate resistant to hydrolysis in $1 \mathrm{~N} \mathrm{HCl}$ at $100^{\circ}$ for $3 \mathrm{hr}$. and, more specifically, in an enzymic assay in which it was converted to lactic acid with the concomitant oxidation of DPNH on the addition of purified preparations of enolase, phosphoenolpyruvokinase, and lactic dehydrogenase. ${ }^{3}$ The oxidation of $\mathrm{DPNH}^{4}$ was followed by the disappearance of its absorption at $340 \mathrm{~m} \mu$. When this assay was to be used directly on the reaction mixture, the enzymes of the skin were denatured by heating at $100^{\circ}$ for $10 \mathrm{~min}$. Figure 2 presents the results of a

${ }^{3}$ These enzymes were purified from rabbit muscle as follows: enolase by the method of Racker (11); phosphoenolpyruvokinase and lactic dehydrogenase as described by Kornberg and Pricer (12). Phosphoglycerate mutase was apparently present in one of these preparations. This method of assay was suggested by Jr. Merton F. Utter.

${ }^{4}$ DPNH was prepared as described by Gutcho and Stewart (13). 
typical assay, and in addition shows that FDP and PG do not interfere in this determination.

$\alpha P G$ was determined as organic phosphate stable in $1 N \mathrm{IICl}$ at $100^{\circ}$ for 3 hr. but hydrolyzable at this acid concentration within $1 \mathrm{hr}$. at $100^{\circ}$ subsequent to exposure to periodate (14). The values obtained were corrected upward for the $10 \%$ of the $\beta$-isomer which is reported as being present in the equilibrium mixture after heating in acid solution (15). Lactic acid was determined colorimetrically (16).

$C^{14}$ was measured in a gas-phase proportional counter (17) after conversion of the compound to $\mathrm{CO}_{2}(18) . P^{32}$ was assayed by drying the samples on aluminum planchets and counting with a Geiger-Müller end-window tube.

\section{Sources of Compounds Used}

The following compounds used in this work were obtained as indicated: AMP and FDP from the Schwarz Laboratories, Inc.; ADP from the Sigma Chemical Co.; ATP and DPN from Pabst Laboratories; F6P, G6P, G1P, and 3PGA from Nutritional Biochemicals Corp., and $\alpha$ PG from the Eastern Chemical Corp. 3PGAld and DHAP (as the cyclohexylammonium dimethyl ketal) ${ }^{5}$ were gratefully received from Dr. Clinton E. Ballou; PEP from Dr. Merton F. Utter and hexokinase from Dr. Richard L. Potter. The DHAP derivative was also obtained from the California Foundation for Biochemical Research as was the DPNH used during the last phases of the study. The aldolase used was a product of the Worthington Biochemicals Corp.

$\mathrm{G} 6 \mathrm{P}-1-\mathrm{C}^{14}$ and $\mathrm{G} 6 \mathrm{P}-6-\mathrm{C}^{14}$ were synthesized enzymically from glucose-1-C $\mathrm{C}^{14}$ and glucose-6-C ${ }^{11}$ (oblained from Nuclear-Chicago Corp. and the National Bureau of Standards, respectively) with purified hexokinase in the presence of ATP and purified by chromatography on filter paper using the acid solvent and on the anion exchanger described above.

FDP-1,6-C'14 (equally labeled in both carbons) was obtained from the NuclearChicago Corp.

\section{Results ANd Discussion}

\section{Conversion of Hexose Phosphate to Phosphoglyceric Acid and Phosphoglycerol}

Incubation of FDP with the "crude extract" in bicarbonate buffer in the presence of fluoride and trace amounts of DPN and Pi results in the quantitative conversion of the substrate to an equimolar mixture of PGA and PG within $60 \mathrm{~min}$. (Table I). One micromole of $\mathrm{CO}_{2}$ is evolved from the buffer for each micromole of FDP which disappears. Under the experimental conditions used, the $\mathrm{CO}_{2}$ is initially evolved at a rate of 80 $\mu$ moles $/ \mathrm{hr} . / \mathrm{mg}$. protein nitrogen. The data in Table I were obtained by separating the products of the reaction and the unreacted FDP (after removal of the denatured protein) first on a column of Dowex $1\left(\mathrm{HCOO}^{-}\right)$ by elution with $\mathrm{NH}_{4} \mathrm{OOCH}$ and then by filter-paper chromatography using the basic solvent. The PGA is probably mostly 3PGA, but no attempt has been made to determine whether or how much $2 \mathrm{PGA}$ was formed in this or any of the experiments to be discussed below. Increasing the con-

5 The ketal was converted to the free compound as described by Ballou and Fischer (19) . 
TABLE I

Stoichiometry of the Conversion of FDP and G6P to PGA and $P G$ Catalyzed by the "Crude Extract"

\begin{tabular}{cccccc}
\hline \multirow{2}{*}{ Expt. No } & \multicolumn{5}{c}{$\Delta$ mmoles/ml. reaction mixture } \\
\cline { 2 - 6 } & FDP & G6P & $\mathrm{CO}{ }^{a}$ & PGA & PG \\
\hline 1 & -6.5 & & +6.6 & +6.3 & +5.9 \\
2 & -6.9 & & +7.2 & +7.4 & +6.5 \\
3 & & -57 & +5.5 & +5.1 & +5.0
\end{tabular}

${ }^{a} \mathrm{CO}_{2}$ evolved from the buffer was measured manometrically. For additional experimental details see the text.

centration of DPN to twice that of the substrate does not alter the stoichiometry of the system. Addition of $\mathrm{AMP}, \mathrm{Mg}^{++}$, pyruvate, and nicotinamide [cf. (20)] have no effect. Raising the Pi concentration to twice that of the substrate serves to depress slightly the rate of reaction but appears to have no other effect. G6P is converted to the same products as arise from FDP (Table I). As shown in Fig. 3, the rate of acid formation, as indicated by the evolution of $\mathrm{CO}_{2}$ from the buffer, is similar for G1P, G6P, F6P, and FDP $\left(10^{-3} M\right.$ ATP was included in the reaction mixtures $)$, and the net amount of $\mathrm{CO}_{2}$ liberated is $1 \mu$ mole/ $\mu$ mole substrate originally present. The latter results are supporting evidence for the presence of phosphoglucomutase, phosphohexoisomerase, and phosphofructokinase.

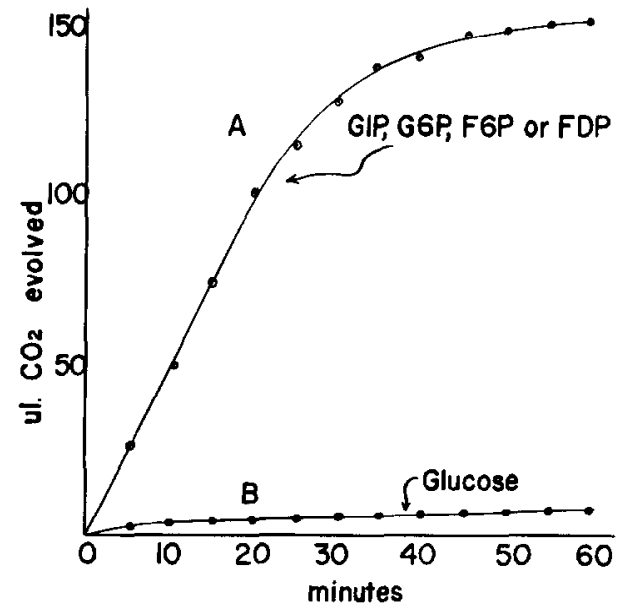

Fra. 3. Acid production with hexose phosphates as substrates by the "crude extract." Curve $A: 7 \times 10^{-3} M$ G1P, G6P, F6P, or FDP plus $10^{-3} M$ ATP and usual components. Curve $B: 7 \times 10^{-3} M$ glueose plus $10^{-3} M$ ATP or $10^{-3} M$ ATP alone and usual components. For further details see the text. 


\section{Formation of Phosphoglycerol from Fructose Diphosphate, Phosphoglyceraldehyde and Dihydroxyacetone Phosphate}

Table II shows the results of experiments on the formation of $\mathrm{PG}$ from FDP, PGAld, and DHAP in the presenee of excess DPNH using a "crude extract." The reactions were followed in the spectrophotometer using the following mixture: $1.2 \times 10^{-4} M$ FDP or $3.8 \times 10^{-4} M$ DHAP or $2.8 \times$ $10^{-4} M$ PGAld; $10^{-1} M$ Tris buffer, $\mathrm{pH} 7.8 ; 1.7 \times 10^{-4} M$ DPNH and 0.12 ml. "crude extract" filtrate (previously incubated with $0.02 M$ potassium iodoacetate at $37^{\circ}$ for $30 \mathrm{~min}$.) per $3 \mathrm{ml}$. final volume. FDP results in the formation of two molar equivalents of $\mathrm{PG}$ and the oxidation of two molar equivalents of DPNH. PGAld and DHAP each result in the formation of one molar equivalent of $\mathrm{PG}$ with the concurrent oxidation of one molar equivalent of DPNH. In addition, two molar equivalents of triose phosphate, determined as "alkali-labile" phosphate, are formed for each equivalent of FDP disappearing when the reaction is carried out as described by Taylor et al. (21) for assay of aldolase. When FDP-1,6-C ${ }^{14}$, G6P-1-C ${ }^{14}$, and G6P-6- $\mathrm{C}^{14}$ are used as substrates under conditions when both PG and PGA are formed, each of the products has essentially half the specific activity (counts/min./ $/$ mole compound) of the hexose phosphate (Table III). The presence of aldolase, triosephosphate isomerase, and a "DPN-

TABLE II

Formation of $P G$ from FDP, PGAld and DHAP in the Presence of Excess DPNH For incubation conditions and assay procedures see the text.

\begin{tabular}{cccc}
\hline & \multicolumn{3}{c}{$\Delta \mu \mathrm{moles} / \mathrm{ml}$} \\
\hline \multicolumn{2}{c}{ Substrate } & DPNH $^{a}$ & PG \\
\hline FDP & -0.12 & -0.27 & +0.25 \\
PGAld & -0.28 & -0.25 & +0.24 \\
DHAP & -0.38 & -0.39 & +0.36 \\
\hline
\end{tabular}

${ }^{a}$ The initial linear rate of oxidation of DPNH was $0.02 \mu \mathrm{mole} / \mathrm{min}$. with FDP or DHAP as substrate and $0.01 \mu \mathrm{mole} / \mathrm{min}$. with PGAld.

TABLE III

Conversion of FDP-1,6-C $C^{14}, G 6 P-1-C^{14}$ and $G 6 P-6-C^{14}$ to $P G A-C^{14}$ and $P G-C^{14}$ For incubation and assay conditions see the text.

\begin{tabular}{|c|c|c|c|c|}
\hline \multirow{2}{*}{ Substrate } & \multicolumn{4}{|c|}{ Counts $/ \mathrm{min} . / \mu$ mole } \\
\hline & FDP & G6P & PGA & $\mathrm{PG}$ \\
\hline FDP-1,6-C 14 & 25,400 & & 12,700 & 12,700 \\
\hline G6P-1-C $\mathrm{C}^{14}$ & & 30,800 & 14,200 & 15,700 \\
\hline G6P-6-C 14 & & 38,500 & 20,000 & 19,900 \\
\hline
\end{tabular}


requiring" glycerophosphate dehydrogenase (22) would explain these observations.

\section{Formation of Phosphoglyceric Acid from Fructose Diphosphate and Triose Phosphate}

As indicated above, $1 \mu$ mole PGA is formed $/ \mu$ mole FDP utilized by the "crude extract" in the presence of fluoride and trace amounts of DPN and $\mathrm{Pi}$. The formation of this acid is decreased by $90-100 \%$ by prcincubation of the extract with $6 \times 10^{-3} M$ potassium iodoacetate, for $30 \mathrm{~min}$. at $25^{\circ}$. (The formation of $\mathrm{PG}$ is inhibited by between 85 and $90 \%$.) If the conversion of FDP to PGA proceeds by the classical glycolytic enzymes, FDP would be split to DHAP and PGAld; PGAld oxidized to 1,3 diPGAboth DPN and Pi being required -and the 1,3 diPGA converted to $3 P G A$ with the concomitant phosphorylation of ADP. However, no formation of ATP could be demonstrated with the "crude extract" either by chromatographic procedures or as an increase in " 7 -min. acid-hydrolyzable" phosphate or by the incorporation of $\mathrm{Pi}^{32}$ - possibly resulting from the presence of a highly active ATPase. Incubation of FDP in the usual medium plus $\mathrm{P}^{32}$ resulted in the incorporation of $60 \%$ of the total radioactivity equally into the PGA and PG, while preincubation of the "crude extract" with iodoacetate depressed this incorporation by better than $90 \%$.

The formation of radioactive PGA and PG could be explained by the incorporation of $\mathrm{Pi}^{32}$ into 1,3-di-PGA-1-P32 the transitory formation of ATP-P ${ }^{32}$, and the formation of FDP-1-P ${ }^{32}$ from F6P and ATP ${ }^{32}$ catalyzed by phosphofructokinase. PGA and PG formed from FDP-1-P ${ }^{32}$ should be labeled since triosephosphate isomerase is present. To get F6P from FDP, however, would require a FDP-phosphatase. This enzyme could not be demonstrated in the "crude extract." Another explanation could involve the formation of $\mathrm{G}^{3} \mathrm{P}^{32}$ from glucose and $\mathrm{ATP}^{32}$; however, the phosphorylation of glucose was not mediated by the system used for the conversion of FDP to PGA plus PG (Fig. 3). A third possibility would be the formation of $\mathrm{G}_{1} \mathrm{P}^{32}$ from glycogen and $\mathrm{Pi}^{32}$, catalyzed by phosphorylase. No attempt was made to investigate this latter point. Glycogen could be expected to pe present in the extract since glycogen has been isolated from the skin of such young rats. ${ }^{6}$ The presence of phosphorylase has not been demonstrated in young rat skin to our knowledge, but Smirnova (23) has reported its occurrence in extracts of guinea pig skin.

Since the "crude extract" contained triosephosphate isomerase and a very active, DPN-linked glycerophosphate dehydrogenase, arsenate had to be present [cf. (24)] in order to observe spectrophotometrically the reduction of DPN resulting from the oxidation of PGAld to PGA. An

${ }^{5}$ Unpublished. 
initial rate of $1.9 \times 10^{-2} \mu \mathrm{mole} / \mathrm{min} . / \mathrm{mg}$. protein nitrogen was obtained with the following components: $3 \times 10^{-3} M$ PGAld or DHAP, $3.3 \times 10^{-2}$ $M$ Tris buffer, $\mathrm{pH} 8.5,2 \times 10^{-2} M$ fluoride, $3 \times 10^{-3} M \mathrm{DPN}, 4 \times 10^{-3} M$ cysteine, $1.7 \times 10^{-2} M$ arsenate and $0.2 \mathrm{ml}$. "crude extract" in a final volume of $3 \mathrm{ml}$. FDP could replace the triose phosphates. The " $60 \%$ $\left(\mathrm{NH}_{4}\right)_{2} \mathrm{SO}_{4}$ supernatant," however, was found to have negligible glycerophosphate dehydrogenase activity (aldolase was also absent), and with the same components an initial rate of $180 \mu \mathrm{moles} / \mathrm{min} . / \mathrm{mg}$. protein nitrogen was attained. With the latter preparation it was possible to show in the absence of arsenate that ADP and Pi were necessary for the oxidation of PGAld to PGA (Fig. 4). $\mathrm{Mg}^{++}$was shown to stimulatc the systcm. In addition, it was possible to show that for each micromole of PGAld (or DHAP) oxidized, $1 \mu$ mole each of DPNH, PGA, and ATP was formed and $1 \mu$ mole Pi disappeared (Table IV). The components for these experi-

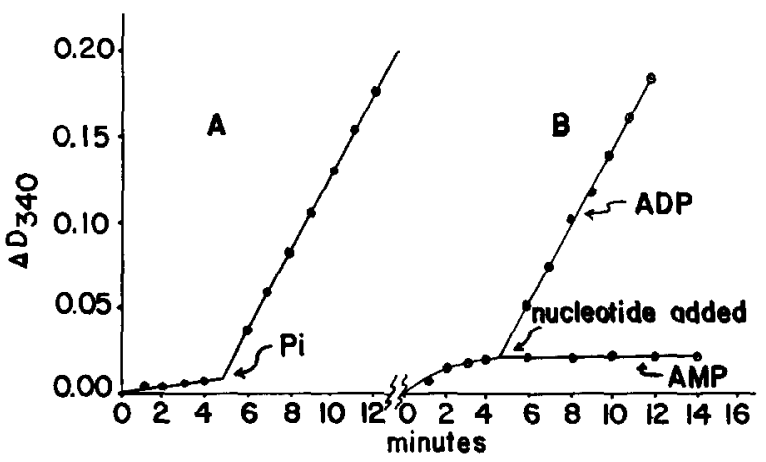

Frg. 4. Effect of $\mathrm{Pi}(A)$ and ADP $(B)$ on the oxidation of triose phosphate by the "60\% $\left(\mathrm{NH}_{4}\right)_{2} \mathrm{SO}_{4}$ supernatant." All components except $\mathrm{Pi}$ in experiment of Curve $A$ and ADP (or AMP) in experiment of Curve $B$ were present at zero time.

\section{TABLE IV}

Conversion of DHAP to PGA.

$\Delta \mu \mathrm{moles} / \mathrm{ml}$.

For incubation and assay procedures see the text.

\begin{tabular}{ccccc}
\hline DHAP & DPNH & Pi & ATP & PGA \\
-0.075 & +0.075 & -0.070 & - & - \\
$a$ & +0.130 & -0.160 & +0.16 & +0.17 \\
& +0.110 & -0.110 & +0.11 & $+0.12^{b}$ \\
\hline
\end{tabular}

a FP plus purified aldolase used in this experiment.

${ }^{b} \mathrm{Pi}^{32}$ was used in this experiment and the data were as follows: $\mathrm{Pi},-7770$ counts/ min.; ATP, -7920 counts/min., and PGA, 0 counts/min. For assay procedures see the text. 
ments were: $3.3 \times 10^{-3} M$ DHAP, $3.3 \times 10^{-4} M \mathrm{MgCl}_{2}, 6.7 \times 10^{-4} \mathrm{M}$ Pi, $4 \times 10^{-3} M$ cysteine, $2 \times 10^{-2} M$ fluoride, $3 \times 10^{-3} M$ DPN, $3.3 \times$ $10^{-2} M$ Tris buffer, $\mathrm{pH} 8.5,5 \times 10^{-4} M \mathrm{ADP}$ and $0.1 \mathrm{ml}$. of " $60 \%\left(\mathrm{NH}_{4}\right)_{2^{-}}$ $\mathrm{SO}_{4}$ supernatant" per final volume of $3 \mathrm{ml}$. To show the need for $\mathrm{Pi}$ and the stimulatory effect of $\mathrm{Mg}^{++}$, the "60\% $\left(\mathrm{NH}_{4}\right)_{2} \mathrm{SO}_{4}$ supernatant" was dialyzed at $0^{\circ}$ for $5 \mathrm{hr}$. against a mixture of $3.3 \times 10^{-2} \mathrm{M}$ sodium pyrophosphate and $3 \times 10^{-3} \mathrm{H}$ cysteine adjusted to $\mathrm{pH} 8.5$. When a large-scale experiment was carried out with $\mathrm{Pi}^{32}$ in order to determine the yield of PGA and ATP, a trace amount of $\mathrm{P}^{32 .}$ was found in the PGA fraction eluted from the ion-exchange column. This radioactivity was not in PGA since it became inorganic when submitted to $1 \mathrm{~N} \mathrm{HCl}$ at $100^{\circ}$ for $10 \mathrm{~min}$. A trace amount of 1,3-di-PGA, labeled in position one, would produce such a result. The presence of triosephosphate dehydrogenase and phosphoglyceric acid kinase would account for the data obtained.

\section{Conversion of Phosphoglyceric Acid to Lactic Acid}

In the initial experiments on FDP utilization, substrate quantities of pyruvate were added in order to make use of lactic dehydrogenase for the reoxidation of DPNH (20). It was expected that FDP would be converted to 2 equiv. PGA which would not be further utilized since enolase was blocked with fluoride. The DPNH formed would then be reoxidized in the conversion of pyruvate to lactate thus necessitating only trace amounts of DPN. Almost no lactate was formed, however, and instead the DPNH was found to be reoxidized by glycerophosphate dehydrogenase.

When 3PGA is incubated in the presence of ADP, DPNH, and $\mathrm{MgCl}_{2}$ with "crude extract" (previously incubated with iodoacetate), it is possible to demonstrute the formation of lactate. Figure 5 indicates the data obtained in such an experiment. The conversion of PEP and pyruvate to lactate is also shown. An amount of $0.54 \mu$ mole lactate was found by colorimetric assay per $0.5 \mu$ mole PGA initially present $(0.528 \mu$ mole DPNH was oxidized), and $0.090 \mu$ mole lactate was found per $0.1 \mu$ mole pyruvate put in $(0.087 \mu$ mole DPNH was oxidized). These data are cvidence for the existence in the extract of enolase, phosphocnolpyruvokinase, and lactic dehydrogenase. The presence of phosphoglyceric acid mutase must he assumed if the data are interpreted as favoring the presence of enolase.

From Fig. 5 it is evident that in the conversion of PCid to lactate, the rate-limiting step is in the formation of PEP, assuming the latter compound to be an intermediate, since the rate of DPNH oxidation is about one-fifteenth as great on PGA as on PEP (hoth measured with the "crude extract" under conditions of maximum rate). The physiological importance of the observation cannot be assessed from the data available. 


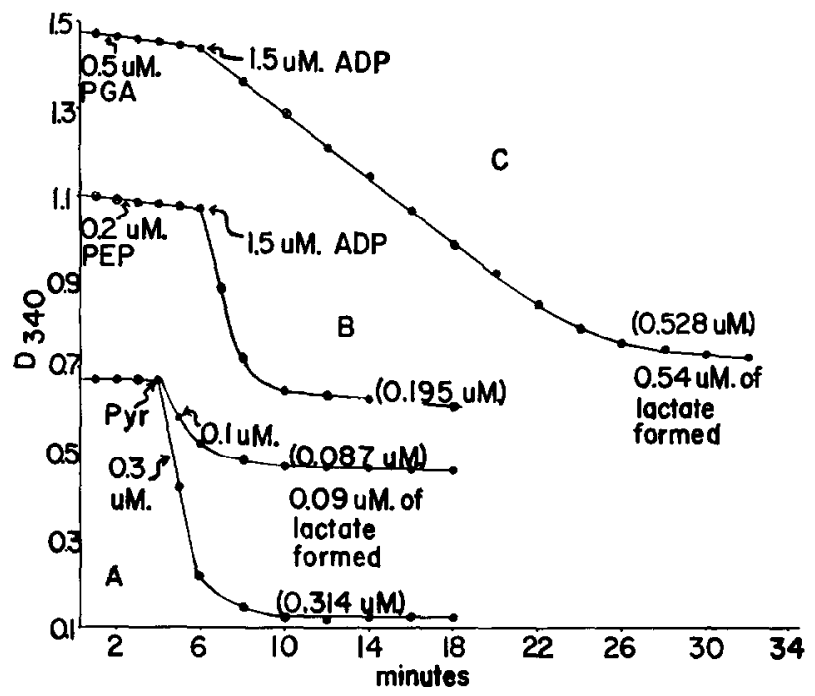

Fig. 5. Spectrophotometric demonstration of enolase, phosphoenolpyruvokinase, and lactic dehydrogenase. Figures in parentheses indicate total amounts of DPNH oxidized in the respective experiments. Components per $3 \mathrm{ml}$. final volume: (a) 0.1 $\mu$ mole or $0.3 \mu$ mole pyruvate; $100 \mu$ moles potassium phosphate buffer, $\mathrm{pH} 7.8 ; 0.35$ $\mu$ mole DPNH; and, $0.05 \mathrm{ml}$. filtered "crude extract." (b) $0.2 \mu$ mole PEP; $100 \mu$ moles potassium phosphate buffer, $\mathrm{pH} 7.8 ; 0.55 \mu$ mole DPNH, $1.5 \mu$ moles ADP; $1 \mu$ mole $\mathrm{MgCl}_{2}$; and $0.05 \mathrm{ml}$. filtered "crude extract." (c) $0.5 \mu$ mole PGA; $1.5 \mu$ moles ADP; $0.75 \mu$ mole DPNH; $1 \mu$ mole $\mathrm{MgCl}_{2} ; 100 \mu$ moles potassium phosphate buffer, $\mathrm{pH} 7.8$; and $0.2 \mathrm{ml}$. filtered "crude extract" previously incubated with iodoacetate $(0.3$ ml. filtered "crude extract" plus $0.1 \mathrm{ml}$. of $0.06 \mathrm{M}$ iodoacetate for $30 \mathrm{~min}$. at room temperature). All reactions were run at $37^{\circ} .-\Delta D_{340}$ of 2.07 corresponds to oxidation of $1 \mu$ mole DPNH.

\section{Phosphorylation of Glucose}

Although the "crude extract" does not phosphorylate glucose from ATP to a significant extent (Fig. 3), the formation of hexose phosphate as assayed by TPNH formation with G6P dehydrogenase is demonstrable by preparing the extract in 1.5 vol. of a mixture of $15 \times 10^{-2} \mathrm{M} \mathrm{KCl}, 5 \times$ $10^{-3} M$ EDT $\Lambda$, and $5 \times 10^{-3} M \mathrm{MgCl}_{2}$ at $\mathrm{pH} 7.0$ (25). In a particular experiment, $3.3 \mu$ moles G6P was formed from $5.0 \mu$ moles glucose in the presence of $1.5 \times 10^{-2} M$ ATP, $8 \times 10^{-3} \mathrm{M} \mathrm{MgCl}_{2}, 0.2 M$ Tris buffer, pH 7.0, $3.3 \times 10^{-3} M$ EDTA, and $0.9 \mathrm{ml}$. extract per $3 \mathrm{ml}$. final volume. Other workers have also reported the presence of hexokinase in rat skin [cf. $(1,2)]$.

\section{ACKNOWLEDGMENT}

The authors sincerely appreciate the interest and encouragement of Dr. Arthur C. Curtis during this investigation. 


\section{SUMMARY}

1. Data have been presented which indicate the presence of most of the glycolytic enzymes in the skin of the young rat.

2. A cell-free extract of this tissue will stoichiometrically convert fructose diphosphate to equimolar quantities of phosphoglyceric acid and phosphoglycerol in the presence of fluoride and trace quantities of diphosphopyridine nucleotide and inorganic phosphate under anaerobic conditions. Phosphoglycerol is formed from dihydroxyactone phosphate by a "diphosphopyridine nucleotide"-requiring glycerophosphate dehydrogenase. If $\mathrm{P}^{32}$-labeled inorganic phosphate is used, $60 \%$ of the total radioactivity is incorporated equally into phosphoglyceric acid and phosphoglycerol. This incorporation is inhibited by iodoactate.

\section{Referenches}

1. Barron, E. S. G., Meyer, J., and Mrller, Z. B., J. Invest. Dermatol. 11, 97 (1948).

2. Dixon, M., and Needham, D. M., Nature 158, 432 (1946).

3. Bernstein, I. A., and Block, W. D., Federation Proc. 14, 182 (1955).

4. Bandurski, R. S., ANd Axelrod, B., J. Biol. Chem. 193, 405 (1951).

5. Hurlaert, R. B., Scimitz, H., Brumm, A. F., and Potere, V. R., J. Biol. Chem. 209, 23 (1953).

6. Gomori, G., J. Lab. Clin. Med. 27, 95 (1942).

7. RoE, J. H., J. Biol. Chem. 107, 15 (1934).

8. Slater, E. C., Biochem. J. 63, 157 (1953).

9. Nelson, N., J. Biol. Chem. 153, 375 (1944).

10. Somogyi, M., J. Bial. Chem. 160, 61 (1945).

11. RACKer, E., J. Biol. Chem. 167, 843 (1947).

12. Kornbera, A., And Pricer, W. E., J. Biol. Chem. 193, 481 (1951).

13. Gutcho, S., and Stewart, E. D., Anal. Chem. 20, 1185 (1948).

14. Long, C., And MAquirf, M. F., Biochem. J. 54, 612 (1953).

15. BaILly, M. C., Compt. rend. 208, 443 (1939).

16. Barker, S. B., and Stmmerson, W. H., J. Biol. Chem. 138, 535 (1941).

17. Bernstein, W., and Ballentine, R., Rev. Sci. Instr. 21, 158 (1950).

18. Van Slyke, D. D., and Folch, J., J. Brol. Chem. 136, 509 (1940).

19. Ballou, C. E., and Fischer, H. O. L., J. Am. Chem. Soc. 78, 1659 (1956).

20. Stoesz, P. A., and Le PAge, G. A., J. Biol. Chem. 180, 587 (1949).

21. Taylor, J. F., Green, A. A., and Cori, G. T., J. Biol. Chem. 173, 591 (1948).

22. Baranowski, T., J. Biol. Chem. 180, 535 (1949).

23. Suirnova, M. G., Biokhimiya 21, 445 (1956).

24. Oesper, P., J. Biol. Chem. 207, 421 (1954).

25. Crane, R. K., And Sols, A., in "Methods in Enzymology," (Colowick, S. P., and Kaplan, N. O., eds.), Vol. 1, p. 277. Academic Press, New York, 1955. 